\title{
From Inuit Nunangat to the Marsh: How Climate Change and Environmental Racism Affect Population Health
}

\author{
Christina Norma Torrealba ${ }^{1}$, BSc \\ 1Department of Community Health and Epidemiology, Dalhousie University
}

DOI: https://doi.org/10.15273/hpj.v1i2.10663

\begin{abstract}
It is widely accepted in the scientific community and beyond that climate change presents an immediate and severe threat to human health and well-being. However, the consequences of climate change are not experienced equally across all populations. Black and Indigenous communities are disproportionately exposed to harmful, hazardous, and often toxic activities and pollutants - a form of racial violence known as environmental racism. To understand how environmental racism, exacerbated by climate change, affects population health, I will explore two examples of environmental racism in Inuit Nunangat in the Arctic and in Truro, Nova Scotia. Finally, I will discuss social capital and power in the context of environmental racism-incorporating an eco-social perspective when addressing environmental racism-and the ways in which population health researchers can help narrow the health gap caused by environmental racism and climate change.
\end{abstract}


From Inuit Nunangat to the Marsh: How Climate Change and Environmental Racism Affect Population Health

I, the author, am a settler-student attending Dalhousie University, which is located in Kjipuktuk (Halifax), in Mi'kma'ki-the ancestral and unceded territory of the Mi'kmaq nation. I am White, and I wish to make clear my position as an individual who has personally benefitted from White privilege. The purpose of this paper is to learn from the expertise and experiences of systemically marginalized individuals and groups who are cited throughout this paper, and to further understand my roleand the roles of the institutions with which I am affiliated-in upholding oppressive systems.

\section{Introduction}

The consequences of climate change are not experienced equally across all populations. While wealthy individuals and corporations continue to profit from the exploitation of natural resources, marginalized communities suffer the brunt of the impact. Concerns of rampant environmental racism in Canada were raised by the Canadian Human Rights Commission in the 2020 report of the UN Special Rapporteur on toxics and human rights (United Nations Human Rights Council, 2020). There is a growing body of work on environmental racism in Canada, and the literature on climate changerelated health outcomes is extensive. The current paper aims to bring these two fields of study together, with Solar and Irwin's (2010) social determinants of health framework in mind. In this paper I will explore how environmental racism and the resulting population health inequities are made worse by climate change. I will describe two examples of environmental racism: rising sea levels in Inuit Nunangat in the Arctic, and flooding in three communities in Truro, Nova Scotia. Finally, I will discuss social capital (which refers to the networks and relationships forged between individuals within a population) and power in the context of environmental racism, and the ways in which population health researchers can help narrow the health gap caused by environmental racism and climate change.

\section{Climate Change and Environmental Racism}

It is widely accepted in the scientific community and beyond that climate change presents an immediate and severe threat to human health and well-being. Increasing anthropogenic greenhouse gas emissions (greenhouse gas emissions caused by human activity) cause rising global temperatures and other climatic changes, resulting in adverse health effects worldwide (McMichael et al., 2006). For example, the European heat wave of 2003 led to approximately 70,000 deaths, with the risk of heat-related mortality in Paris increasing by $70 \%$ due to anthropogenic climate change (Mitchell et al., 2016). An epidemiologic review of studies from cities across North and South America, Europe, Australia and Asia found that increasing ambient temperatures were associated with heightened risk of mortality, and that Black people, women, and people in lower socioeconomic positions were particularly vulnerable (Basu, 2009). In Lhasa, China, climate change facilitated the establishment of Culex pipiens complex mosquitoes, which are carriers of a number of diseases including West Nile (Liu et al., 2013). The examples are endless, and the consequences are dire.

Broadly, climate change affects human health through three basic pathways: (a) direct health implications associated with extreme weather events, including flooding, droughts, and storms; (b) health effects mediated via natural systems, including air pollution, and vector-, food- and water-borne diseases; and (c) health effects mediated via human systems, including food insecurity, displacement, mental health challenges, and violence and conflict (McMichael et al., 2006; Smith et al., 2014). In this paper, I will mainly explore the third pathway, linking climate change to social, economic, and demographic disturbances, and their subsequent effects on health.

Canadian environmental policies and legislature often negatively target racialized populations, particularly Black, Indigenous, and 
People of Colour (BIPOC). Black and Indigenous communities are disproportionately exposed to harmful, hazardous, and often toxic activities and pollutants, and this is a form of racial violence known as environmental racism (Waldron, 2016). Environmental racism precipitates a multitude of health risks, and these risks are exacerbated by climate change. Environmental racism has become more prominent in discourse surrounding the movement for climate and environmental justice in recent years; however, the issue is often pushed to the side or conflated with other environmental issues. Without input from affected communities and an emphasis on racial justice, environmental activists fail to address the root of environmental racism.

The term environmental racism was coined by American researchers in the 1980s, and much of the existing literature comes from the United States (Jacobs, 2010; Northridge \& Shepard, 1997). There is a lack of literature on the mechanisms by which climate change and environmental racism intersect, and on exactly how environmental racism is intensified by worsening climate change. One example that demonstrates this intersection is the way Black Americans in New Orleans experienced Hurricane Katrina in August of 2005.

Following the hurricane, predominantly Black communities and livelihoods were disproportionately and catastrophically damaged. The contemporary vestige of colonial plantations in New Orleans, or the "White Teapot," is a collection of predominantly White neighbourhoods that are situated at high elevations, far from riverside and backswamp nuisances (Morse, 2008). Conversely, predominately Black neighbourhoods in New Orleans were built at low elevations, at high risk of flooding from swamps and rivers and isolated due to the location of federal housing and poor access to transportation (Morse, 2008). These factors made Black communities more vulnerable to hurricane-related flooding than White communities. Not only were Black communities disproportionately damaged by Hurricane Katrina, but they also dealt with the disparities for far longer than White people who were affected by the hurricane. On August 31st, what is considered the final day of the weather event, $67 \%$ of Black residences in New Orleans were flooded, compared to $51 \%$ of White residences. Over one week later, on September 8 th, $60 \%$ of Black residences remained flooded compared to $24 \%$ of White residences (Morse, 2008). From this example it is clear how environmental racism and the resulting disparities in health, safety and security-in this case, the geographic location and lack of infrastructure for Black communities-were exacerbated by an extreme weather event, which is likely to occur more frequently and can be more severe due to climate change.

An understanding of the "complex web of inequalities" (Waldron, 2018, p. 92) is necessary to understand how environmental racism affects Black and Indigenous communities. Structural determinants of health approaches emphasize the need for a holistic view of health inequalities, including socioeconomic position, food insecurity, housing, social class, education, biological factors, gender, and so forth (Solar \& Irwin, 2010). Therefore, when assessing environmental racism and climate change, it is crucial to go beyond strictly clinical assessments of health or quantitative measures of physical damage following a storm. Rather, we must tackle overlapping and intersecting stressors that increase vulnerability to environmental dangers in systematically marginalized and racialized groups (Waldron, 2018).

\section{Inuit Nunangat}

Coastal regions are disproportionately impacted by rising sea levels. Today, climate change continues to affect Inuit populations living on coastal Inuit Nunangat, which includes Nunatsiavut, Nunavik, Nunavut and the Inuvialuit Settlement Region. Nunangat means "homeland" in Inuktitut, and refers to the land, water, and ice in the aforementioned four regions (Oceans North, n.d.). Due to environmental racism, colonial violence, intergenerational trauma and forced cultural assimilation, there are vast disparities in health between Inuit and non-Inuit in Canada. Culture 
is a key component in a healthy community, and the loss of a traditional culture and language can be detrimental to social capital, knowledge translation, and ultimately, health (Greenwood et al., 2015). Inuit living in Inuit Nunangat have an average life expectancy of 67.3 years, compared to the national Canadian average of 79.5 years (Harper et al., 2012). The rates of suicide and self-inflicted injury among Inuit are almost 10 times higher than the national average, and all-cause mortality (standardized by age) is almost 40 times higher among Inuit than the national average (Harper et al., 2012). With population health inequities already a major cause for concern among Inuit, the severe and complex effects of climate change further negatively influence these disparities. In Rigolet, Nunatsiavut, $88 \%$ of surveyed community members reported that climatic and environmental changes were concerning, with $76 \%$ reporting that climate change had resulted in changes to their health (Harper et al., 2012).

The health-related impacts of climate change manifest in Inuit Nunangat in a number of ways, including decreased personal safety, increased food and water insecurity, and poor mental health (Ford et al., 2014). Climate change leads to rapidly changing weather and melting sea ice, making land, sea and ice conditions difficult to predict and thus increasing one's risk of injury or death while travelling and hunting in Inuit Nunangat (Ford et al., 2014). Moreover, accessing health care and emergency medicine can be extremely difficult in Inuit Nunangat, further increasing health and fatality risks associated with climate change. With the changing environment, Inuit livelihoods are also at risk, as hunting, fishing, culture, diet and wellbeing are detrimentally impacted (Ford et al. 2014; Harper et al., 2012).

Food insecurity is another major concern among Inuit: there is a lack of access, availability, and quality of food in Inuit Nunangat. Hunting, fishing, and gathering are important aspects of Inuit culture, and traditional foods, including seal, beluga whale, caribou, Arctic char and wild berries, are staples of contemporary Inuit diets (Ford, 2009). Traditional foods and traditional modes of food preparation are culturally and economically significant, nutritious, and sustainable. They are important mechanisms of social capital and community building, with food sharing within and between households guided by kinship rules (Ford, 2009). Over the past few decades, store-bought foods have become a more popular part of the Inuit diet, which poses a number of challenges in Inuit Nunangat. Most of Inuit Nunangat is only accessible by air, winter roads, and boat (only in the summer), making it extremely challenging to deliver non-perishable food items and fresh produce (Ford, 2009). All of these modes of travel are weather dependent, and are thus vulnerable to climate change and unpredictable weather. Similarly, traditional food acquisition is vulnerable to climate change as hunting becomes more challenging due to changes in snowfall, melting sea ice and availability of certain animals, leading to new or worsening problems of food insecurity (Ford, 2009; Ford et al., 2014). Food insecurity is associated with a number of negative health outcomes, including vitamin and mineral deficiencies, poor self-rated health, dental problems, and mental illness (Gundersen \& Ziliak, 2015).

Moreover, respiratory disease-related mortality is approximately five times higher among Inuit living in Inuit Nunangat compared to the Canadian average, and rates of tuberculosis are over 290 times higher among Inuit, compared to non-Indigenous Canadians (Harper et al., 2012; Patterson et al., 2018). The root causes of these disproportionate rates of respiratory disease lie in the social and structural determinants of health, particularly in insufficient housing. Over half (52\%) of Inuit live in social housing, which often sees upwards of 20 people sharing a four-bedroom house (Patterson et al., 2018). Most dwellings are overcrowded, in dire need of repairs, infested with mould, and "below housing standards" (Bell, 2020, para 12). The housing crisis in Inuit Nunangat and lack of response from the federal government is an example of systemic racism. As stated by Mumilaaq Qaqqaq, formerly Nunavut's New Democratic Party MP, "the whole system keeps Inuit oppressed” (Bell, 2020, para 18). 
Climatic and environmental changes in ambient temperature are predicted to worsen the effects of respiratory diseases, including tuberculosis, in part due to forced displacement and inadequate housing (Smith et al., 2014). These inequities intersect to situate Inuit in an extremely vulnerable position in relation to the negative effects of climate change on respiratory health.

Despite these gaps in population health and well-being, the Canadian government has invested a limited budget in climate changerelated health research and policy changes, with inadequate resources allocated to Indigenous communities in the North (Ford et al., 2014). According to Ford et al. (2014), "this investment represents a small fraction of other federal expenditures and is insufficient for a problem as complex and potentially damaging to human and environmental health as climate change" ( $p$. e10). The lack of support for Inuit, who are being disproportionately affected by climate change and ongoing colonial violence, is an example of environmental racism on the part of the Canadian government. Local action is ongoing: traditional knowledge of hunting practices, food sharing networks, land-based knowledge, and the incorporation of traditions and cultures into health practices are all ways in which Inuit are resilient, despite resistance and lack of support from the government (Ford et al., 2014).

Notably, in discussing anti-Indigenous environmental racism, it is critical to recognize the significance of the land to Indigenous peoples:

To indigenous peoples, land is not just physical and biological environment. The land is the ash of their ancestors who fought to keep the land from becoming destroyed by others: the ancestors on whose shoulders we stand in this generation, whose land we must preserve for the next seven generations. (Colomeda \& Wenzel, 2000, p. 249)

For Inuit, strong relationships with the environment and land are critical in maintaining culture, traditions and well-being. In a study that interviewed Community Health Representatives
(CHRs) from First Nation and Inuit communities in Canada, environmental/cultural connections were identified as one of six primary determinants of health (Richmond \& Ross, 2009). Debbie, a CHR, gives the following explanation:

In my community, we are more northern and we have traditional foods that we depend on. We travel on the land, we socialize more together, and we know each other, and that is good. We always go on word of mouth, if somebody is going through this or that, and this means everybody gets involved. We are lucky to have that. (Richmond \& Ross, 2009, p. 407)

Inuit Qaujimajatuqangit, which translates to "that which Inuit have always known to be true" (Tagalik, 2009-2010, p. 1), refers to knowledge, systems of beliefs, and values in Inuit cultureit is a living, dynamic episteme. As climate change drastically impacts the land in Inuit Nunangat, systems of traditional knowledge translation like Inuit Qaujimajatuqangit-a key cultural determinant of health-are at risk. Community members, Elders, and hunters have expressed concerns with the unpredictable climate and how it will impact transportation and traditional routes of travel. Sytukie Joami, a community member from Iqaluit, describes the changes they have witnessed: "It is getting more unpredictable as to what will happen; because the signs are misleading the Inuit who are used to weather that follows these signs" (Nunavut Climate Change Centre, n.d.). Environmental dispossession and reduced access to traditional territories are associated with decreased access to social capital and cultural and intermediary determinants of health, thus negatively impacting health outcomes (Ford et al., 2014; Greenwood et al., 2015). Furthermore, when examining determinants of Indigenous peoples' health in Canada, colonialism is viewed as the single most important determinant of health for many Indigenous peoples (Waldron, 2018). Greenwood et al. (2015) argue that current frameworks of social determinants of health tend to exclude colonialism, spirituality, 
relationship to the land, knowledge systems and other determinants of health that are not necessarily social. Incorporating colonialism into current frameworks will be more complicated than simply adding colonial violence to a list of determinants. It will require an intersectional, cross-cutting understanding of how colonialism interacts with other determinants of health, including gender, ethnicity, social capital, societal values, and culture.

\section{The Marsh, the Island, and the Hill}

Precipitation, snow cover, soil moisture content, sea levels, glacial lake conditions, and vegetation are all factors that both affect flood characteristics and are affected by climate change (Seneviratne et al., 2012). Over the past few decades, flood frequency has increased across the world, as has the risk of extreme flooding. These changes can be partially attributed to changes in the climate (Seneviratne et al., 2012). Extreme flooding can destroy homes, hospitals, crops, and transportation, all the while increasing rates of infectious diseases, including cholera, respiratory infections, and vector-borne diseases (Ohl \& Tapsell, 2000). The literal and figurative rebuilding that must occur after floods causes lasting emotional trauma and psychological stress (Ohl \& Tapsell, 2000).

Flooding has been a major issue for the Marsh, the Island and the Hill-three historically African Nova Scotian neighbourhoods in Truro, Nova Scotia. Each neighbourhood is named after the land that encompasses it, as described by a community member of the Island and referenced by Millman (2019):

[...] when the Black people came to Truro, they weren't allowed to live in town, they put them on the Marsh, where it was marshy, way over the Hill, where it was hilly and trees, and they put us up here because apparently when it used to rain, or whatever, the water used to surround $i t$. That's how it got called the Island. ( $p$. 42)
Due to rising river levels and increased rainfall, fluvial and pluvial floods are becoming more prevalent in these communities, bursting dikes and detrimentally impacting livelihoods (Corfu, 2016; Segal, 2014; Tutton, 2012). Residents of the communities have expressed concerns about the impacts of the floods, but have had little to no support from government bodies at the municipal, provincial, and federal levels. Anthropogenic climate change results in unpredictable and potentially more dangerous instances of flooding and other extreme weather events, and there are therefore growing concerns of how flooding will continue to impact African Nova Scotian communities in Truro.

For coastal regions like Nova Scotia, flooding will become more frequent with climate change. The Nova Scotia Department of Environment has expressed concern about the increased flooding, but the emphasis seems to be on protecting infrastructure rather than communities. According to a representative of the Nova Scotia Department of Environment, the flooding can be better managed and there is a lot of progress to be made "especially in areas where we have critical infrastructure that we need to protect" (Pace, 2015, para 11). Meanwhile, the general conclusion from the 2015 Atlantic Flood Management Conference in Truro was that "people in the region need to adapt" (Pace, 2015, para 1). Many community members from the Marsh were repeatedly displaced as a result of flooding and were forced to move into rental housing, as they could not afford to repair their flood-damaged homes (Waldron, 2016). Inexplicably, many were not eligible for flood insurance, despite how frequently floods occur in the area (Waldron, 2018). The health, safety, and well-being of Black community members has been directly and disproportionately impacted by the floods, but the emphasis on rebuilding and protection remains focused toward infrastructure and away from communities.

Furthermore, one of the major concerns among residents of the Marsh, the Island, and the Hill is the lack of African Nova Scotian representation and involvement in policymaking in Truro (Waldron, 2018). Residents 
receive little support or response from the government, compared to their wellrepresented White counterparts, as described by an African Nova Scotian community member from Truro and referenced by Waldron (2016): And as white people move into the communities, whether it's the Island, the Hill or the Marsh, they start to do things to enhance ... perception to enhance the area. Whereas, as long as it was predominantly a Black area, they just left it as it was and figured, you know, we don't do anything to enhance the area or to improve the area. But, as soon as one white person moves into the area, then all of a sudden, "okay, let's see what we can do." (p. 14)

A lack of action and collaboration from the government amplifies racial hierarchies and health inequities in the area, clearly illustrating how social policies are failing African Nova Scotians. The difference in the response between when a White community is vulnerable to flooding and when a Black community is vulnerable shows how "climate change is set to exacerbate existing disregard for Black life, in part through the very universalism embedded in the claim that 'all lives matter'" (Sealey-Huggins, 2018, p. 101).

\section{Social Capital and Power}

It is important to examine the concept of social capital in the context of environmental racism. As described by Solar and Irwin (2010), social capital acts as a link between structural (socioeconomic position, social class, racism, etc.) and intermediary (behaviours, biological factors, psychosocial factors, etc.) determinants of health. Putnam (2000, p. 67) defines social capital as the "features of social organization, such as networks, norms and social trust, that facilitate coordination and cooperation for mutual benefit." In the context of environmental racism and climate change, strong social capital among members of a community is health protective, in the sense that a community network and mutual respect are beneficial to one's well-being. Furthermore, co-operative relationships among groups in different positions along a gradient of power (referred to as linking social capital) is an important aspect of health policy (Solar \& Irwin, 2010). Collaborative efforts between community members and policy-makers are one mechanism through which environmental racism can be addressed.

Social capital, however, is a controversial term. Muntaner (2004) argues that social capital is used by public and population health researchers as a comforting metaphor that implies that capitalism and social cohesion can somehow work together harmoniously. As Muntaner maintains, "capitalism creates competition and inequality, and thus tends to erode social integration" (p. 675). Climate change is fueled by capitalismand colonialism and imperialism. Capitalism shapes economic systems and policies, with profit and economic growth prioritized at the expense of environmental justice and population health (Sealey-Huggins, 2018). Therefore, in the context of environmental racism and climate change, perhaps social capital is not the best terminology to use. Instead, the term "social cohesion" and other similar terms are distinct from capitalism, and holistically sum up the important communitydriven pathways that protect health (Muntaner, 2004). Social cohesion emphasizes networks and relationships among communities beginning at a societal level, whereas descriptions of social capital typically begin at the individual level.

Going beyond the discussion of social capital, and what I argue is more important in addressing environmental racism and climate change, is the redistribution of power. In the discourse of health determinants, the central role of power refers to the political contexts and social, public, and economic policies that engage both the agency of marginalized and disadvantaged populations and the accountability of the state (Solar \& Irwin, 2010). Theories of power in regard to health equity are grounded in theories of human rights, based heavily in the discipline's prevailing emphasis on the need for restoring power to oppressed 
and marginalized populations. Empowerment and the equal distribution of power are central to the rights to health and to have control and autonomy over one's own health. Fundamentally, environmental racism is one mechanism through which racialized groups are stripped of their power and resources via systemic disempowerment, unjust distribution of power along White supremacist ideals, and violation of rights to health and health autonomy.

\section{Moving Forward}

When considering how to best address the connected issues of climate change and environmental racism, I want to recognize that much of the work is already underway. Community members have been advocating for themselves and their communities and continue to do so. What is missing is the support, funding, and collaboration from policy-makers. Waldron (2016) references an African Nova Scotian community member from Truro who described government inaction in regard to the flooding:

Every year I try to address the flood with government. And even to the Town representatives. And, it gets back with trying-'We're trying'. That's been going on for over 60 years. And, the big problem with that is we have no political clout. We have no political organizations in our community. But, if we had an organization speaking on behalf of the communities, that would have a lot more clout. (p.22)

The disconnect between the needs of the community and environmental policy-making prohibits the improvement of health outcomes in racialized communities.

In reference to the environmental justice movement, Waldron (2018) writes: "Those agendas [of environmental activists] often seek to subsume environmental racism within the broader (and more comfortable) environmental justice lens, in which racism gets displaced from its rightful place at the centre" (p. 15). To echo Waldron, there is no environmental justice without racial justice, and environmental racism should thus be viewed as a distinctive mechanism of injustice. Similarly, I argue that environmental racism should be viewed as a distinct determinant of health in the study of epidemiology and population health, especially as climate change continues to be a prominent and growing area of research and policy. More quantitative and qualitative community-led research is needed in order to adequately assess the intersection of environmental racism and climate change in Canada.

Theory matters when defining social epidemiology and analyzing epidemiological trends (Krieger, 2001). The eco-social perspective emphasizes the need to consider social, biological, historical and ecological factors as intersectional influences on health that cannot be considered in isolation (Krieger, 2001). Krieger proposes six multi-level pathways to explain the connections between racial discrimination, violence, and biological embodiments of poor health: (a) economic and social deprivation, (b) toxic substances and hazardous conditions, (c) socially inflicted trauma, (d) targeted marketing of commodities, (e) inadequate health care, and (f) resistance to racial oppression (Krieger, 2001). We can situate environmental racism within the first and second pathways. In the two examples that I described, racialized communities were deprived of economic and social resources (e.g., food, proper housing, traditional knowledge) and were subject to hazardous conditions (e.g., flooding, melting sea ice). Through these pathways, Krieger emphasizes that differences in biology and health outcomes are not a result of race, but a result of racism. It is racism that leads to disproportionate numbers of landfills in African Nova Scotian communities; racism that drives decades-long boil-water advisories on Indigenous reserves; and racism that triggers a quick government response to a disaster in a wealthy White community, but radio silence when that same disaster occurs in a systematically marginalized one.

Climate change negatively and disproportionately impacts population health among racialized groups due to environmental racism. To address the impacts of environmental 
racism and climate change on population health, I believe there are two major actions that must take place. Firstly, there is the redistribution of power. Due to colonialism, socially-inflicted trauma, and socioeconomic inequities, Black and Indigenous communities have been disenfranchised and disempowered by colonial and White supremacist systems. Restoring power to communities is necessary in designing environmental interventions that account for important social and cultural dimensions. Secondly, policy-makers and government bodies must be held accountable for their role in perpetrating environmental racism, both through their action and inaction. As the environmental justice movement continues to grow, support and acknowledgement is needed from all levels. Irrefutably, "the climate crisis is a racist crisis" (\#BlackLivesMatterUK, 2021), and it is the health of systematically racialized and marginalized populations that have suffered and will continue to suffer excessively if trends continue.

\section{References}

Basu, R. (2009). High ambient temperature and mortality: A review of epidemiologic studies from 2001 to 2008. Environmental Health, 8, Article 40. https://doi.org/10.1186/1476-069x-840

\#BlackLivesMatterUK [@ukblm]. (2021, August 9). The climate crisis is a racist crisis \#ClimateEmergency [Tweet]. Twitter. https://twitter.com/ukblm/status/142 4730260684345352?lang=en

Bell, J. (2020, August 24). Nunavut housing crisis an example of systemic racism, MP says. Nunatsiaq News. https://nunatsiaq.com/stories/article/ nunavut-housing-crisis-an-example-ofsystemic-racism-mp-says/

Colomeda, L. A., \& Wenzel, E. R. (2000). Medicine keepers: Issues in Indigenous health. Critical Public Health, 10(2), 243-256. https://doi.org/10.1080/713658247
Corfu, N. (2016, February 16). Truro prepares for heavy rains and possible flooding. CBC News. https://www.cbc.ca/news/canada/nov a-scotia/storm-flooding-truro-mayor1.3450930

Ford, J. D. (2009). Vulnerability of Inuit food systems to food insecurity as a consequence of climate change: A case study from Igloolik, Nunavut. Regional Environmental Change, 9(2), 83-100. https://doi.org/10.1007/s10113-0080060-x

Ford, J. D., Willox, A. C., Chatwood, S., Furgal, C., Harper, S., Mauro, I., \& Pearce, T. (2014). Adapting to the effects of climate change on Inuit health. American Journal of Public Health, 104(S3), e9-e17. https://doi.org/10.2105/ajph.2013.301 724

Greenwood, M., de Leeuw, S., Lindsay, N. M., \& Reading, C. (Eds.) (2015). Determinants of Indigenous peoples' health in Canada: Beyond the social (1st ed.). Canadian Scholars' Press.

Gundersen, C., \& Ziliak, J. P. (2015). Food insecurity and health outcomes. Health Affairs, 34(11), 1830-1839. https://doi.org/10.1377/hlthaff.2015.0 645

Harper, S. L., Edge, V. L., Cunsolo Willox, A., \& Rigolet Inuit Community Government. (2012). 'Changing climate, changing health, changing stories' profile: Using an EcoHealth approach to explore impacts of climate change on Inuit health. EcoHealth, 9(1), 89-101. https://doi.org/10.1007/s10393-0120762-x

Jacobs, B. (2010, May 20). Environmental racism on Indigenous lands and territories. Canadian Political Science Association. https://www.cpsa-acsp.ca/papers2010/Jacobs.pdf

Krieger, N. (2001). Theories for social epidemiology in the 21st century: An ecosocial perspective. International Journal of Epidemiology, 30(4), 668- 
677. https://doi.org/10.1093/ije/30.4.668

Liu, Q., Liu, X., Cirendunzhu., Woodward, A., Pengcuociren., Bai, L., Baimaciwang., Sang, S., Dazhen., Wan, F., Zhou, L., Guo, Y., Wu, H., Li, G., Lu, L., Wang, J., Dawa., Chu, C., \& Xiraoruodeng. (2013). Mosquitoes established in Lhasa city, Tibet, China. Parasites \& Vectors, 6 , Article 224. https://doi.org/10.1186/1756-3305-6224

McMichael, A. J., Woodruff, R. E., \& Hales, S. (2006). Climate change and human health: Present and future risks. The Lancet, 367(9513), 859-869. https://doi.org/10.1016/s01406736(06)68079-3

Millman, P. (2019). African Nova Scotian youth experience on the Island, the Hill, and the Marsh: A study of Truro, Nova Scotia in the 1950s and 1960s (Publication No. 13901920) [Master's thesis, University of Lethbridge]. ProQuest Dissertations Publishing.

Mitchell, D., Heaviside, C., Vardoulakis, S., Huntingford, C., Masato, G., Guillod, B. P., Frumhoff, P., Bowery, A., Wallom, D., \& Allen, M. (2016). Attributing human mortality during extreme heat waves to anthropogenic climate change. Environmental Research Letters, 11(7), Article 074006. https://doi.org/10.1088/17489326/11/7/074006

Morse, R. (2008). Environmental justice through the eye of Hurricane Katrina. Joint Center for Political and Economic Studies, Health Policy Institute.

Muntaner, C. (2004). Commentary: Social capital, social class, and the slow progress of psychosocial epidemiology. International Journal of Epidemiology, 33(4), 674-680. https://doi.org/10.1093/ije/dyh200

Northridge, M. E., \& Shepard, P. M. (1997). Comment: Environmental racism and public health. American Journal of Public Health, 87(5), 730-732.
https://dx.doi.org/10.2105\%2Fajph.87. 5.730

Nunavut Climate Change Centre. (n.d.). Voices from the land-Quotes by community: Iqaluit. https://www.climatechangenunavut.ca /en/knowledge/voices-land

Oceans North. (n.d.). Inuit Nunangat. https://oceansnorth.org/en/where-wework/inuit-nunangat/

Ohl, C. A., \& Tapsell, S. (2000, November 11). Flooding and human health. The BMJ, 321, 1167-1168. https://doi.org/10.1136/bmj.321.7270. 1167

Pace, N. (2015, March 5). Flooding problems won't recede in Atlantic Canada: Experts. Global News. https://globalnews.ca/news/1866192/ flooding-problems-wont-recede-inatlantic-canada-experts/

Patterson, M., Flinn, S., \& Barker, K. (2018). Addressing tuberculosis among Inuit in Canada. Canada Communicable Disease Report, 44(3-4), 82-85. https://doi.org/10.14745/ccdr.v44i34a 02

Putnam, R. D. (2000). Bowling alone: The collapse and revival of American community. Simon \& Schuster.

Richmond, C. A. M., \& Ross, N. A. (2009). The determinants of First Nation and Inuit health: A critical population health approach. Health \& Place, 15(2), 403411. https://doi.org/10.1016/j.healthplace.2 008.07.004

Sealey-Huggins, L. (2018). 'The climate crisis is a racist crisis': Structural racism, inequality and climate change. In A. Johnson, R. Joseph-Salisbury, \& B. Kamunge (Eds.), The fire now: Antiracist scholarship in times of explicit racial violence (pp. 99-116). Zed Books.

Segal, M. (2014, November 27). Truro's Park Street floods again following rain. $C B C$ News. https://www.cbc.ca/news/canada/nov 
a-scotia/truro-s-park-street-floodsagain-following-rain-1.2852673

Seneviratne, S. I., Nicholls, N., Easterling, D., Goodess, C. M., Kanae, S., Kossin, J., Luo, Y., Marengo, J., McInnes, K., Rahimi, M., Reichstein, M., Sorteberg, A., Vera, C., \& Zhang, X. (2012). Changes in climate extremes and their impacts on the natural physical environment. In C. B. Field, V. Barros, T. F. Stocker, D. Qin, D. J. Dokken, K. L. Ebi, M. D. Mastrandrea, K. J. Mach, G.-K. Plattnew, S. K. Allen, M. Tignor, \& P. M. Midgley (Eds.), Managing the risks of extreme events and disasters to advance climate change adaptation: Special report of the Intergovernmental Panel on Climate Change. (pp. 109-230). Cambridge University Press. https://www.ipcc.ch/site/assets/uploa ds/2018/03/SREX-Chap3_FINAL-1.pdf

Smith, K. R., Woodward, A., Campbell-Lendrum, D., Chadee, D. D., Honda, Y., Liu, Q., Olwoch, J. M., Revich, B., and Sauerborn, R. (2014). Human health: Impacts, adaptation, and co-benefits. In C. B. Field, V. R. Barros, D. J. Dokken, K. J. Mach, M. D. Mastrandrea, T. E. Bilir, M. Chatterjee, K. L. Ebi, Y. O. Estrada, R. C. Genova, B. Girma, E. S. Kissel, A. N. Levy, S. MacCracken, P. R. Mastrandrea, \& L. L. White (Eds.), Climate change 2014: Impacts, adaptation, and vulnerability. Part A: Global and sectoral aspects. Contribution of Working Group II to the Fifth Assessment Report of the Intergovernmental Panel on Climate Change. (pp. 709-754). Cambridge University Press. https://www.ipcc.ch/site/assets/uploa ds/2018/02/WGIIAR5-

Chap11_FINAL.pdf

Solar, 0., \& Irwin, A. (2010). A conceptual framework for action on the social determinants of health (Discussion Paper Series on Social Determinants of Health, Paper 2). World Health Organization. https://www.who.int/sdhconference/r
esources/Conceptualframeworkforactio nonSDH_eng.pdf

Tagalik, S. (2009-2010). Inuit

Qaujimajatuqangit: The role of

Indigenous knowledge in supporting wellness in Inuit communities in Nunavut. National Collaborating Centre for Aboriginal Health.

https://www.ccnsanccah.ca/docs/health/FSInuitQaujimajatuqangitWellnessNunavu t-Tagalik-EN.pdf

Tutton, M. (2012, September 10). Dikes burst in Truro as rain swamps N.S. rivers. CTV News. https://atlantic.ctvnews.ca/dikesburst-in-truro-as-rain-swamps-n-srivers- 1.949820

United Nations Human Rights Council. (2020, September 4). Visit to Canada: Report of the Special Rapporteur on the implications for human rights of the environmentally sound management and disposal of hazardous substances and wastes (A/HRC/45/12/Add.1). https://undocs.org/en/A/HRC/45/12/ Add.1

Waldron, I. R. G. (2016, September 10). Experiences of environmental health inequities in African Nova Scotian communities. ENRICH Project. https://www.enrichproject.org/wpcontent/uploads/2016/10/FinalEnvironmental-Racism-Report.pdf

Waldron, I. R. G. (2018). There's something in the water: Environmental racism in Indigenous and Black communities. Fernwood Publishing. 